\title{
Statistical Model for Fluxes of Nutrients from River Runoff into the Ofunato Estuary
}

\author{
Yasuhiro Hayakawa* \\ (Accepted March 10, 1986)
}

\begin{abstract}
Fluxes of dissolved inorganic nitrogen and phosphate from riverine and sewage runoff into the Ofunato estuary were measured to assess nutrient loadings and examine their frequency distribution. The frequency distributions of the discharge and the nutrient concentration were well fitted to the lognormal distributions independent of each other, which led to the lognormal distribution of the nutrient flux. Daily discharges were estimated from daily precipitation data using the multiple regression, and the estimated discharges could demonstrate their seasonal change including the flood after a heavy precipitation. Daily fluxes of nutrients from the river were estimated by a statistical model with a bivariate distribution of the daily discharge and nutrient concentration, and seasonal changes in the estimated mean and standard deviation were sampled. This model provided a strategy to estimate and predict nutrient fluxes more precisely with a more refined regression of each of the daily discharge and the nutrient concentration.
\end{abstract}

An adequate supply of nutrients from rivers is of great importance to maintain high productivities in the estuarine waters. In the Ofunato estuary, riverine and sewage loadings of nutrients have long been a support of aquacultures such as scallops, oysters and algae, but recently turned out to be a threat of pollution. To estimate not only averaged fluxes of nutrients but also their seasonal changes is essential for the preservation of fertile waters. In addition, it is seemed that changes in the river discharge make a greater contribution than those in the nutrient concentration to the variability of nutrient fluxes into this estuary, and there is not any direet relationships between the river discharge and the nutrient concentration.

This paper describes the frequency distribution of the river discharge, the nutrient concentration and the nutrient flux, then thereby estimates the variations in nutrient fluxes using a statistical model combined with the multiple regression of the river discharge.

\section{Materials and Methods}

\section{Study Area}

The Ofunato estuary has a surface area of 7.7 $\mathrm{km}^{2}$, a volume of $1.24 \times 10^{8} \mathrm{~m}^{8}$ at mean low water, and maximum depth of $38 \mathrm{~m}$. The drainage area is $167.1 \mathrm{~km}^{2}$ and the Sakari River watershed area of which is $123.3 \mathrm{~km}^{2}$ flows into the inner part of the estuary as shown in Fig. 1.

To know the outline of nutrient fluxes, water samples were taken at 14 stations (R-1 to $R-14)$, where R-9 and R-10 were the collective stations including several small sewages, and discharges were measured on the 27th to 28th of July in 1980. These stations covered all the riverine and sewage runoffs into the estuary.

To monitor the main sources of nutrient fluxes, water qualities and discharges were measured monthly at the Sakari River (R-1) from April in 1979 to March in 1985, and at the Sakari Sewage (R-2) from April in 1982 to March in 1985. The discharges were calculated based on measurements of velocity profiles using the current meter (TOHO DENTAN, CM1B). Daily precipitation data (from 1978 to 1985) at the Ofunato Weather Station were used to estimate the daily river discharges.

\section{Sample Analysis}

Water samples, filtered through a filter paper (TOYO ROSHI, NO. 6), were analyzed for nitrate, nitrite and phosphate by the method of Strickland and Parsons, ${ }^{1)}$ and ammonia by the method of Nimura. ${ }^{2)}$ Total inorganic nitrogen (TIN) was calculated as the sum of these nitrogen compounds mentioned above. Fluxes of TIN and phosphate

* School of Fisheries Sciences, Kitasato University, Sanriku, Kesen, Iwate 022-01, Japan (早)川康博: 北里 大学水産学部). 


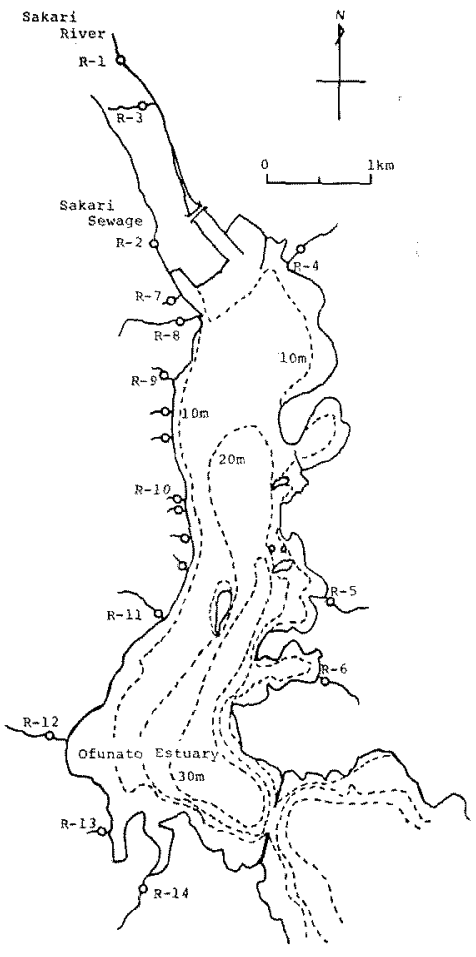

Fig. 1. Map of the Ofunato estuary and location of sampling stations (from R-1 to R-14) for the estimation of nutrient fluxes from the riverine and sewage runoff.

were caleulated as the product of discharge and concentration.
The multiple regression analysis was made to estimate the river discharge and the nutrient flux, using the software (I.B.C., Multivariate Analysis Library I). Other statistical analyses were based on the common method. ${ }^{3)}$

\section{Results}

\section{Outline of Nutrient Flux}

Synoptic measurements at 14 stations in 1980 showed that the Sakari River and the Sakari Sewage formed the major two sources for TIN and phosphate, as is shown in Table 1. The discharge of the Sakari River amounted to $73.6 \%$ of the total discharges of riverine and sewage runoff into this estuary, being close to the ratio of the watershed area of this river to the total drainage area $(73.7 \%)$. Thus this source accounted for $67.2 \%$ and $37.2 \%$ of the total flux of TIN and phosphate, respectively. On the other hand, the Sakari Sewage had high concentrations of nutrients, therefore fluxes of TIN and phosphate amounted to $22.9 \%$ and $39.9 \%$ of the total flux, respectively, in spite of its negligible amount of the discharge. It is clear that most of the discharges, fluxes of TIN and phosphate were supplied from these two sources.

\section{Monitoring of Nutrient Flux}

Changes in the discharge, concentrations of TIN and phosphate at R-1 and R-2 are shown on the logarithmic scale in Fig. 2, together with the data of monthly precipitation.

Table 1. Outline of nutrient fluxes from riverine and sewage runoff into the Ofunato estuary (July in 1980)

\begin{tabular}{|c|c|c|c|c|c|}
\hline \multirow{2}{*}{ Stn. } & \multirow{2}{*}{$\frac{\text { Discharge }}{\left(\mathrm{m}^{3} / \mathrm{s}\right)}$} & \multicolumn{2}{|c|}{ TIN } & \multicolumn{2}{|c|}{ Phosphate } \\
\hline & & $(\mu \mathrm{g}-\mathrm{at} / \mathrm{l})$ & (kg/day) & $(\mu \mathrm{g}-\mathrm{at} / l)$ & (kg/day) \\
\hline R-1 & 4.88 & 139 & 834 & 1.7 & 20.3 \\
\hline R-2 & 0.51 & 584 & 284 & 21.9 & 21.8 \\
\hline R-3 & 0.03 & 144 & 4.3 & 14.4 & 1.0 \\
\hline R-4 & 0.28 & 81.7 & 26.9 & 1.1 & 0.8 \\
\hline R-5 & 0.02 & 24.2 & 0.7 & 0.8 & 0.1 \\
\hline$R-6$ & 0.03 & 59.3 & 2.4 & 2.7 & 0.2 \\
\hline R-7 & 0.09 & 301 & 24.2 & 50.8 & 6.2 \\
\hline $\mathrm{R}-8$ & 0.29 & 51.8 & 19.3 & 0.9 & 0.7 \\
\hline R-9 & 0.05 & 213 & 9.9 & 12.6 & 1.2 \\
\hline R-10 & 0.13 & 76.6 & 12.4 & 4.2 & 1.2 \\
\hline R-11 & 0.03 & 122 & 4.6 & 2.0 & 0.2 \\
\hline R-12 & 0.16 & 32.7 & 6.3 & 1.0 & 0.4 \\
\hline R-13 & 0.06 & 65.6 & 3.6 & 1.6 & 0.2 \\
\hline R-14 & 0.07 & 103 & 8.8 & 1.8 & 0.3 \\
\hline Total & 6.63 & - & 1240 & - & 54.6 \\
\hline
\end{tabular}




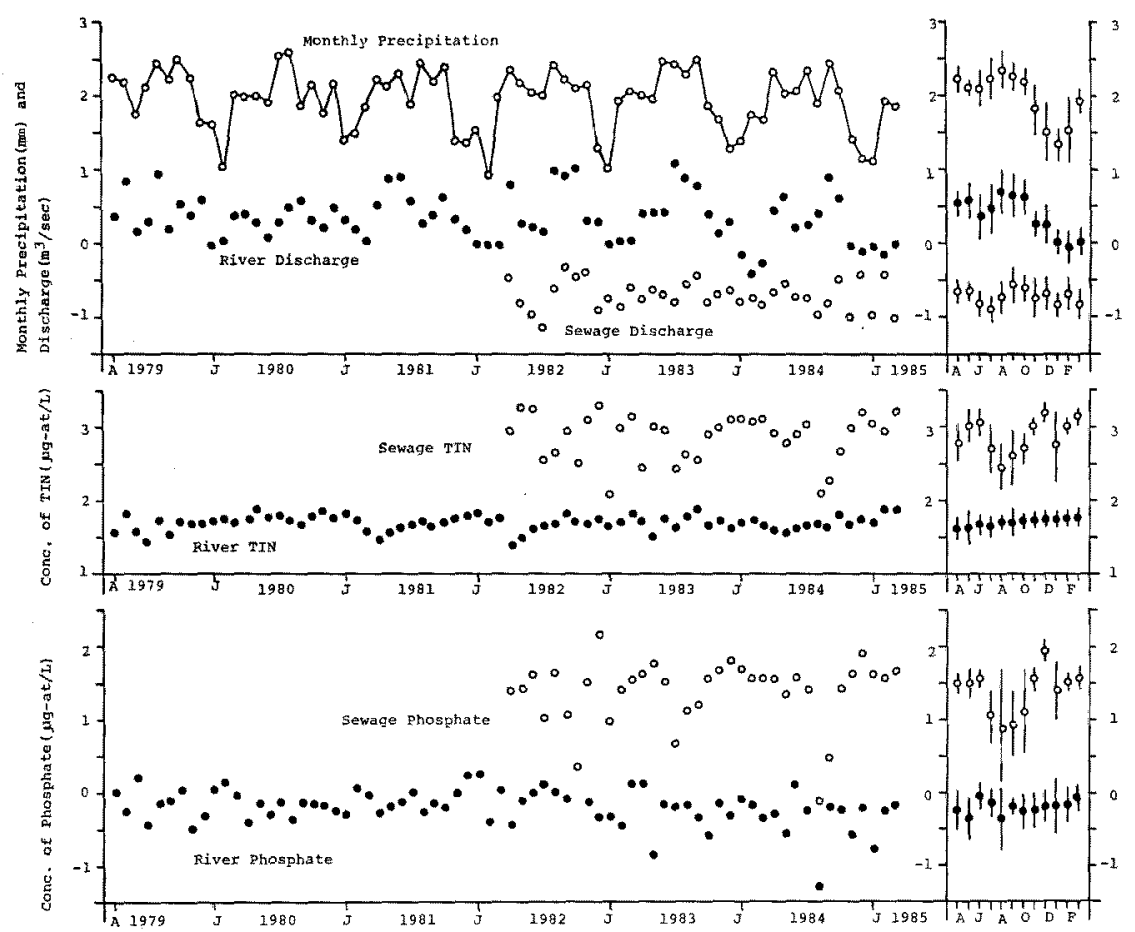

Fig. 2. Changes in monthly precipitation, discharge, concentrations of TIN and phosphate on the common logarithmic scale.

Solid circles denote the Sakari River (R-1), and open circles denote the Sakari Sewage $(\mathbf{R}-2)$. Seasonal means and standard deviations for the monitoring period are presented in the right.

Table 2. Means and standard deviations of the observed data and their common logarithms monitored at the Sakari River (R-1) and the Sakari Sewage (R-2) from April in 1979 to March in 1985

\begin{tabular}{|c|c|c|c|c|c|c|c|}
\hline \multirow[b]{2}{*}{ Stn. } & & \multirow{2}{*}{$\begin{array}{l}\text { Monthly } \\
\text { Precipitation } \\
\text { (mm) }\end{array}$} & \multirow{2}{*}{$\begin{array}{c}\text { Discharge } \\
\left(\mathrm{m}^{3} / \mathrm{s}\right)\end{array}$} & \multicolumn{2}{|c|}{ TIN } & \multicolumn{2}{|c|}{ Phosphate } \\
\hline & & & & $(\mu \mathrm{g}-\mathrm{at} /)$ & (kg/day) & $(\mu \mathrm{g}-\mathrm{at} / l)$ & (kg/day) \\
\hline \multirow[t]{6}{*}{$\mathrm{R}-1$} & No. of data & 72 & 72 & 72 & 72 & 72 & 72 \\
\hline & Mean & 134 & 3.26 & 52.2 & 202 & 0.7 & 5.7 \\
\hline & S.D. & 98 & 2.89 & 12.6 & 189 & 0.4 & 5.2 \\
\hline & Common Log. & & & & & & \\
\hline & Mean & 1.98 & 0.37 & 1.71 & 2.16 & -0.22 & 0.58 \\
\hline & S.D. & 0.41 & 0.35 & 0.11 & 0.35 & 0.26 & 0.41 \\
\hline \multirow[t]{5}{*}{ R-2 } & No. of data & - & 36 & 36 & 36 & 36 & 36 \\
\hline & Mean & - & 0.21 & 912 & 227 & 33.5 & 18.1 \\
\hline & S.D. & - & 0.10 & 511 & 160 & 25.0 & 14.2 \\
\hline & $\begin{array}{l}\text { Common Log. } \\
\text { Mean }\end{array}$ & - & -0.72 & 2.87 & 2.23 & 1.37 & 1.08 \\
\hline & S.D. & - & 0.21 & 0.32 & 0.39 & 0.45 & 0.50 \\
\hline
\end{tabular}

By applying the two-way layout method in analysis of variance ( $F$-test) to observed data themselves and common logarithms of the data, it was tested whether seasonal and annual changes were significant or not at less than $5 \%$ level. As a result, seasonal changes in precipitation and 
river dischage were found significant at $1 \%$ level. Those in riverine fluxes of TIN and phosphate were significant at $1 \%$ and $5 \%$ level, respectively. None of annual changes were found among the riverine data. So, there were neither annual nor seasonal changes in the nutrient concentrations of the Sakari River. As for the Sakari Sewage, neither annual nor seasonal changes in the logarithms of the observed discharge, nutrient concentrations and nutrient fluxes were significant. However, being applied to the data themselves, seasonal changes in concentrations of TIN and phosphate and the flux of phosphate were significant at $1 \%$ level. Seasonal changes mentioned above might be shown in a series of seasonal means and standard deviations in Fig. 2.

By applying the test of significance for correlation coefficients $(t$-test) to the observed data and their common logarithms, correlations between the discharge and nutrient concentrations were tested at less than $5 \%$ level. None of correlation coefficients were significant between any two of the discharge, concentrations of TIN and phosphate in the Sakari River. Only the sewage concentrations of TIN and phosphate correlated with each other at $1 \%$ level. So, riverine and sewage discharges did not correlated with either of nutrient concentrations.

Statistics of both observed data and their common logarithms are shown in Table 2. The arithmetric mean of TIN (52.2 $\mu \mathrm{g}-\mathrm{at}-\mathrm{N} / l)$ in the river was composed of ammoniaf $\mathrm{N}(2.9 \mu \mathrm{g}-\mathrm{at}-\mathrm{N} / l)$, nitrite- $\mathrm{N}(0.5 \mu \mathrm{g}$-at- $\mathrm{N} / l)$ and nitrate $\mathrm{N}(48.8 \mu \mathrm{g}$ at-N $/ I)$, while the mean sewage TIN $(912 \mu \mathrm{g}$-at$\mathrm{N} / l$ ) was derived from ammonia of 817 , nitrite of 29.7 , and nitrate of $64.8 \mu \mathrm{g}$-at- $\mathrm{N} / \mathrm{l}$. Most of
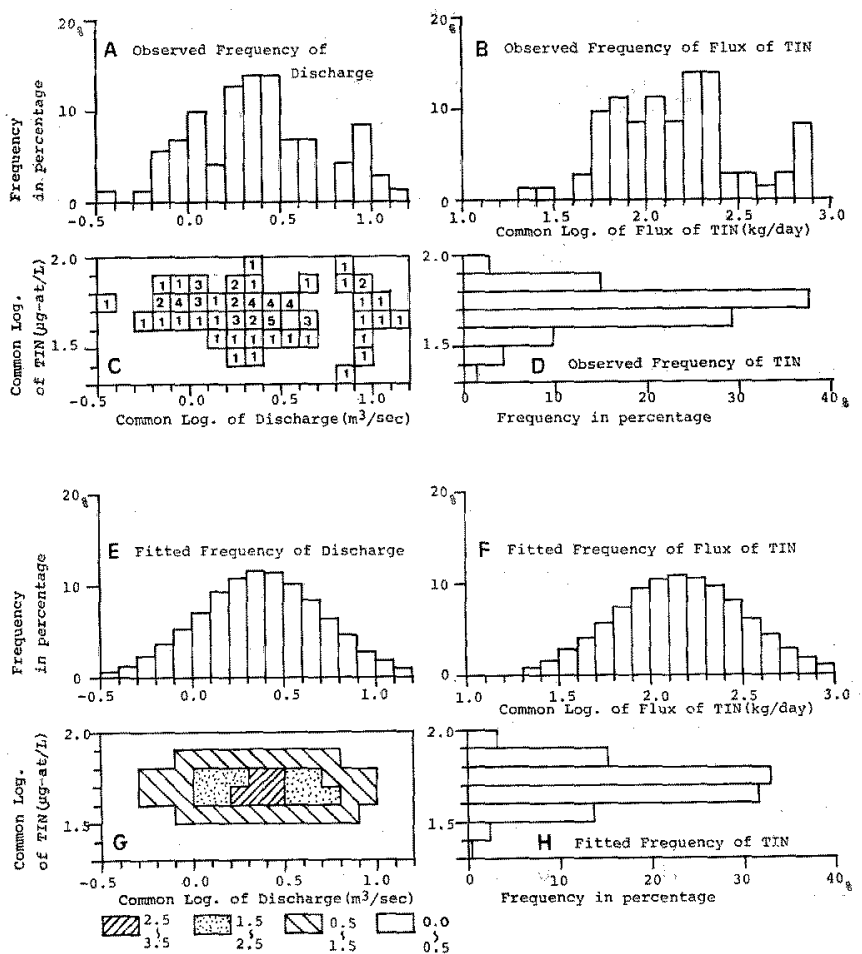

0.5

Fig. 3. Frequency distributions of discharge, TIN concentration and TIN flux at the Sakari River.
A: Observed frequency of the river discharge.
B: Observed frequency of TIN flux.
C: Bivariate distribution of the observed data.
D: Observed frequency of TIN concentration.
E: Lognormal distribution fitted to the observed discharge.
F: Lognormal distribution fitted to the observed TIN flux.
G: Bivariate lognormal distribution of discharge and TIN concentration.
H: Lognormal distribution fitted to the observed TIN concentration.
The number of data is 72 . 
riverine TIN was accounted for by nitrate-N, and ammonia-N predominated in the sewage. The sum of discharges, fluxes of TIN and phosphate from these two sources amounted to $3.47 \mathrm{~m}^{3} / \mathrm{s}$, $429 \mathrm{~kg}-\mathrm{N} /$ day, and $23.8 \mathrm{~kg}-\mathrm{P} /$ day, respeetively.

\section{Frequency Distribution}

By application of the test of goodness of fit (chi square test) to the common logarithms of data, the hypothesis was tested at less than $5 \%$ level that the observed frequency was fitted to a lognormal distribution. In calculating the chi square values, data were grouped into the intervals of 0.1 or 0.2 on the common logarithmic scale.

Suppose that $X, Y$, and $Z$ denote the river discharge, the concentration of nutrient, and the fux of nutrient, respectively. Since the lognormal distribution is equivalent to the normal distribution of common logarithms of the data, the observed frequency distribution of $X$ was fitted to the following,

$$
F(\log (X))=N\left(M X, S X^{2}\right)
$$

where $F$ is a probability density function and $N$ is a normal distribution with its mean of $M X$ and standard deviation of $S X$. The sample mean of 0.37 as $M X$, and the sample standard deviation of 0.35 as $S X$ were taken to approximate the observed frequency distribution of $\log (X)$ to the normal one.

Also, the observed frequency of nutrient concentration was fitted to the next formula,

$$
F(\log (Y))=N\left(M Y, S Y^{2}\right)
$$

where $M Y$ and $S Y$ are the mean and the standard deviation of $\log (Y)$, respectively. The sample mean of 1.71 as $M Y$, and the sample standard deviation of 0.11 as $S Y$ were taken for approximation of the observed frequency of riverine TIN concentrations.

It is clear that $\log (Z)$ is given by,

$$
\log (Z)=c+\log (X)+\log (Y)
$$

where $c$ is a constant value relating to the unit. If units of $\mathrm{m}^{3} / \mathrm{s}, \mu \mathrm{g}$-at- $\mathrm{N} / l$, and $\mathrm{kg}-\mathrm{N} /$ day are for $X, Y$, and $Z$, respeetively, $c$ is the value of 0.08 .

Since there was not any significant correlation between $\log (X)$ and $\log (Y)$ in this river, it was assumed that $\log (X)$ and $\log (Y)$ were independent of each other. Then the frequency distribution of $\log (Z)$ was theoretically given by the next formula, owing to the reproductive property of the normal distribution;

$$
F(\log (Z))=N\left(M X+M Y+c, S X^{2}+S Y^{2}\right)
$$

where the mean and the standard deviation of $\log (Z)$ were given by calculation. As for the flux of TIN, the formula (4) was given by $N(2.16$, $0.37^{2}$ ), to which the observed frequency of $\log (Z)$ with its mean of 2.16 and standard deviation of 0.35 was fitted. Each fitting of observed frequencies of $\log (X), \log (Y)$, and $\log (Z)$ to the normal distributions was good, as is illustrated in Fig. 3. It was shown that the riverine TIN flux was characterized by the lognormal distribution, which was due to the lognormal ones of both the discharge and TIN concentration.

In the same way, the observed frequency distribution of the riverine phosphate flux was fitted well to the lognormal distribution of the formula (4) with the mean of 0.58 and the standard deviation of 0,44 .

As for the sewage flux, the flux of TIN was fitted well to the lognormal distribution with the mean of 2.23 and the standard deviation of 0.38 . However the phosphate flux was not fitted to the lognormal distribution, because of its abnormal frequency of phosphate concentrations that were greatly affected by irregular domestic sewages.

\section{Multiple Regression of River Discharge}

By the method of the multiple regression, the daily discharge of the Sakari River was estimated, using the data of the daily precipitation and the river discharges observed monthly from April 1979 to March 1985. In multiple regression I, the daily average of river discharge $(R)$ is given by a linear model,

$$
R=a+\sum_{i}\left(b_{i} \times P_{1}\right)+E, \quad(i=1 \text { to } 7)
$$

where $a$ is a constant value, $P_{i}$ is the daily precipitation of $i$ days ago, $b_{i}$ is a partial regression coefficient for $P_{i}$, and $E$ is a random variable characterized by a normal distribution with its mean of zero and a constant standard deviation. Only 7 days' precipitation data would be insufficient to estimate daily river discharges preeisely. On calculation, however, the multiple correlation coefficient was 0.86 , the residual standard error was $1.57, a$ was 1.43 , and $b(i=i$ to 7) were $0.098,0.096,0.072,0.033,0.040,0.020$, and 0.046 , respectively, when the unit of $R$ was $\mathrm{m}^{3} / \mathrm{s}$ and that of $P_{1}$ was $\mathrm{mm}$. Values of $b_{i}$ were significant at $1 \%$ level in $F$-test, except for $b_{5}$ and $b_{0}$.

In multiple regression $\mathrm{II}$, a log-linear model is given by,

$$
\log (R)=e+\sum_{i}\left(f_{i} \times P_{i}\right)+E, \quad(i=1 \text { to } 7)
$$




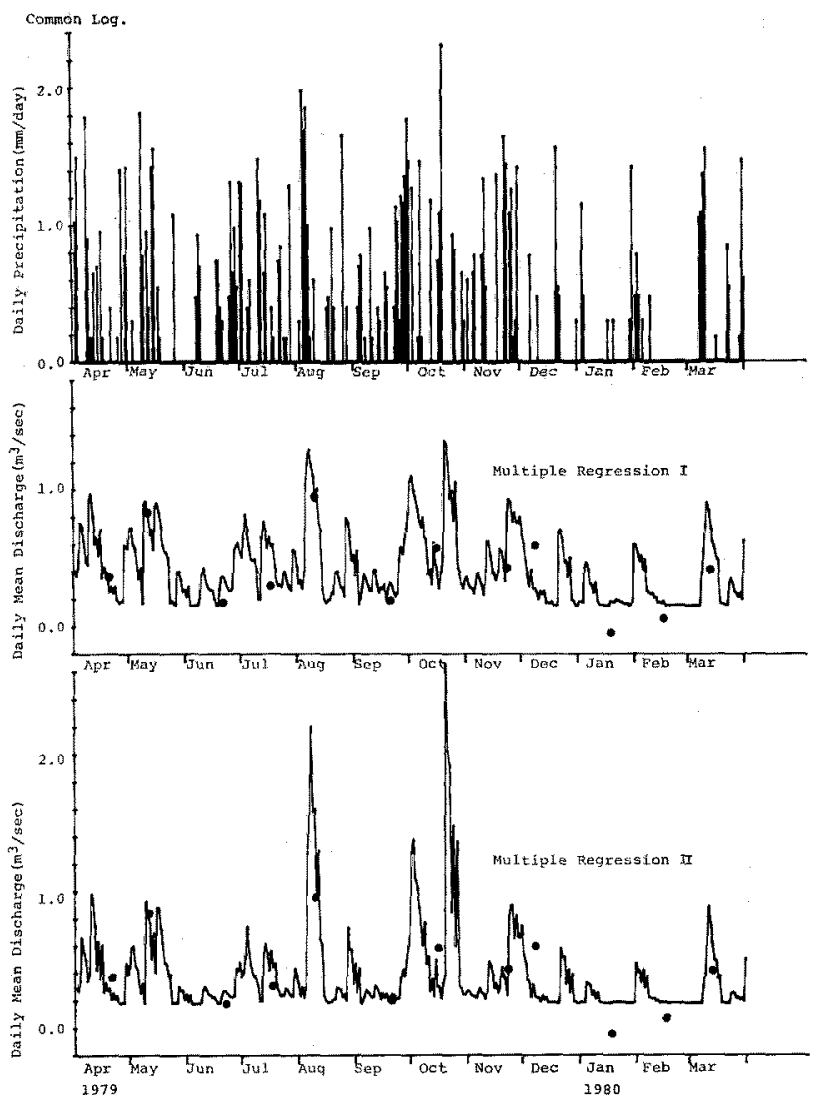

Fig. 4. Estimation of daily mean discharges at the Sakari River. Note that daily precipitation plus one are plotted on the common logarithmic scale. Solid circles show the observed discharges.

where $\log (R)$ is the common logarithms of the daily discharge, $e$ is a constant value and $f_{i}$ is a partial regression coefficient for $\boldsymbol{P}_{i}$. The multiple correlation coefficient was 0.75 , the residual standard error was $0.24, e$ was 0.18 , and $f_{t}$ $(i=1$ to 7 ) were $0.011,0.009,0.009,0.003,0.006$, 0.002 , and 0.006 , respectively. Values of $f_{i}$ were significant at $1 \%$ level, except for $f_{4}, f_{5}$, and $f_{6}$.

An example of estimated daily dischrges from April in 1979 to March in 1980 is shown in Fig. 4. The arithmetric mean of 6 years' daily discharges (2192 estimators) was $3.23 \mathrm{~m}^{3} / \mathrm{s}$ in the multiple regression $\mathrm{I}$, and $4.25 \mathrm{~m}^{3} / \mathrm{s}$ in the multipie regression II. Fortunately, these estimated means were close to the observed mean $\left(3.26 \mathrm{~m}^{3} / \mathrm{s}\right)$, though the estimated discharge in flood just after a heavy precipitating was taken into consideration on the one hand, and monthly observations were made avoiding the flood on the other hand. But the frequency distribution of the estimated daily discharges for 6 years was not necessarily fitted to the lognormal distribution to which the frequency of the discharges observed monthly was fitted well. This incompatibility seemed to be derived from non-linear relationship between discharge and precipitation, especially in the dry season, when no precipitation for 7 days did not always result in a constant discharge, but estimation by the regression model resulted in a constant discharge of the residual, as was given by $a$ or $e$ in the formula (5) or (6). Nevertheless, these regression models seemed to be useful to a certain extent for estimating the mean and the standard deviation of the daily river discharge.

\section{Statistical Model for Daily Nutrient Flux}

By the analogy of the frequency distribution based on the nutrient flux for 6 years, the daily nutrient flux in an individual day was estimated under the following assumptions. 


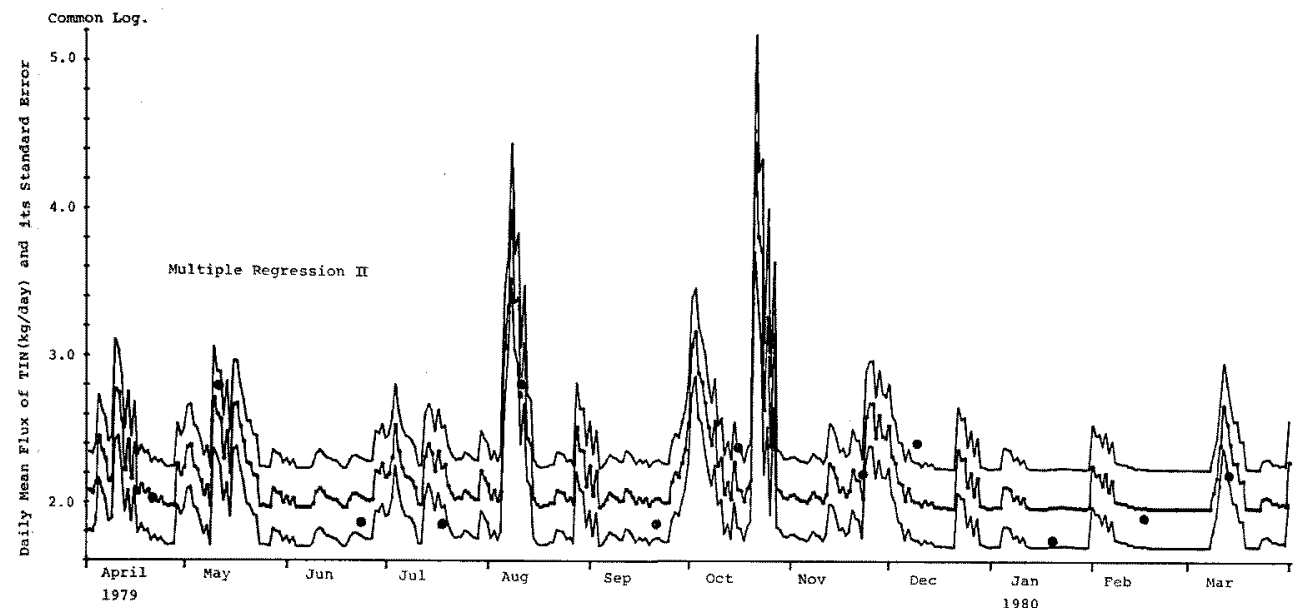

Fig. 5. Estimation of daily mean fluxes of TIN and their standard errors at the Sakari River. Solid circles are the observed fluxes of TIN.

1) The daily river discharge $(R)$ and the daily nutrient concentration $(C)$ are characterized by a joint distribution,

$$
F(\log (R), \log (C))=N\left(M R, M C, S R^{2}, S C^{2}, r\right)
$$

where $N$ is a bivariate normal distribution, $M R$ and $S R$ are the mean and standard deviation of $\log (R)$, $M C$ and $S C$ are those of $\log (C)$, and $r$ is a simple correlation coefficient between two variables.

2) The frequency distribution of $\log (R)$ is theoretically given by the normal distribution $N\left(M R, S R^{2}\right)$, and then $M R$ is estimated by the furmula (6) of the multiple regression II, and $S R$ is estimated by the next formula, ${ }^{3)}$

$$
\begin{gathered}
S R=R S \times \sqrt{1+1 / n+\sum_{i} \sum_{j}\left(Q_{i j} \times\left(P_{i}-M P_{i}\right)\right.} \\
\overline{\left.\times\left(P_{j}-M P_{j}\right)\right)}, \quad(i, j=1 \text { to } 7)
\end{gathered}
$$

where $R S$ is the residual standard error of the estimated $\log (R), n$ is the number of data used in the regression II, $M P_{i}$ and $M P_{j}$ are the means of $P_{i}$ and $P_{j}$, respectively, and $Q_{i j}$ is the $i-j$ component of the inverse matrix of the matrix of sum of squares and products derived from deviations of observed precipitations.

3) The frequency distribution of $\log (C)$ is also the normal distribution $N\left(M C, S C^{2}\right)$, and $M C$ and $S C$ are taken as observed values, if there is no correlation between $\log (R)$ and $\log (C)$, but otherwise they may be estimated by some regression.

Under these assumptions, it follows that the frequency distribution of the daily nutrient flux $(W)$ is given by the next integration, taking the same relation between the variables as formula (3) into consideration;

$$
\begin{aligned}
G(U) & =\int_{-\infty}^{\infty} F(U-V-c, V) \cdot d V=N(M R \\
& \left.+M C+c, \quad S R^{2}+S C^{2}+2 r \cdot S R \cdot S C\right)
\end{aligned}
$$

where $U$ and $V$ are $\log (W)$ and $\log (C)$, respectively, and $G(U)$ is a probability density function of the log-transformed nutrient flux. Especially, if $\log (C)$ is independent of $\log (R)$, or $r$ equals zero, formula (9) gives $N\left(M R+M C+c, S R^{2}+\right.$ $S C^{2}$ ), equivalent to formula (4).

On estimating the daily nutrient flux from the Sakari River into the estuary, it was assumed that the discharge and the nutrient concentration were independent of each other. The regression II gave $M R$ and $S R$ to characterize the daily discharge, while $M C$ and $S C$ were given by Table 2 . The formula (9) gave a series of daily nutrient fluxes with their daily means and standard deviations.

An example of TIN flux from April 1979 to March 1980 is shown in Fig. 5. The arithmetric average of estimated daily fluxes for 6 years was $261 \mathrm{~kg}-\mathrm{N} /$ day, and that of phosphate fluxes was $6.9 \mathrm{~kg}-\mathrm{P} /$ day.

\section{Discussion}

On estimating the daily nutrient flux, it is necessary to evaluate both discharge and nutrient concentration. As for the river discharge, the multiple regression I was better fitted to the observed discharge than the regression II. However, the multiple regression II was chosen to estimate the 
daily discharges, partly because it still had a good correlation coefficient of 0.75 and partly because it was such a simple log-linear model that it could estimate the daily discharges only from the previous precipitations and characterize their lognormal distribution. The other alternative regression will do, if it exceeds the regression II in predicting the daily discharge precisely and characterizing its lognormal distribution. Nevertheless, the regression II was useful for estimating the daily discharges. And it seemed to be possible to refine the regression II with many observations including data in the flood period as well as in the dry and cold winter with intermittent snow.

In estimating nutrient concentrations, the following three cases should be discussed.

1) When $r$ is zero, the frequency distribution of $\log (W)$ is given by $N\left(M R+M C+c, S R^{2}+\right.$ $S C^{2}$ ) where $M C$ and $S C$ are to be estimated from observations. This case was studied here on the dissolved nutrients in the Sakari River.

2) When $r^{2}$ is between zero and one, there is a certain correlation between discharges and nutrients concentrations. In most cases, the nutrient concentration is characterized by a linear regression,

$$
\log (C)=m+k \cdot \log (R)
$$

where $m$ and $k$ are constants, to which Stevens and Smith $^{4}$ fitted the observed nitrogen and phosphorus fractions successfully. An estimate of $M C$ and $S C$ would be made by the formula (10), and thus obtained bivariate normal distribution of formula (7), upon which the above linear regression is reflected though the value of $r$, introduces the frequency distribution of $\log (W)$ as is given by the formula (9). A positive correlation increases the standard deviation and vice versa. When a polynomial regression of the nutrient concentration on the discharge that was tested by Smith and Stewart ${ }^{5 /}$ holds good, the formula (9) could still give a frequency distribution of $\log (W)$ as long as the linear regression of formula (10) is a close approximation of the polynomial one inside the rather narrow range of the daily discharge in an individual day.

3) When $r^{2}$ is one, there is an exact correlation between $\log (R)$ and $\log (C)$, that is given by the formula (10). The frequency distribution of $\log (C)$ is given by the normal distribution of $N$ $\left(m+k \cdot M R, k^{2} \cdot S R^{2}\right)$ instead of the assumption 3). And that of $\log (W)$ is directly given by the normal distribution of $N(c+m+(k+1) \cdot M R$, $\left.(k+1)^{2} \cdot S R^{2}\right)$, under the assumption 2) alone. In this case, the assumption 2) is wide enough for the others to be abolished.

It would be possible to make more precise estimate and prediction of daily nutrient fluxes from this statistical model, with the regression of the discharge and/or nutrient concentration much refined by many observations.

\section{Acknowledgements}

The author wishes to thank the former students of School of Fisheries Sciences, Kitasato University, for measuring nutrient fluxes. This study was partly supported by the grant No. 576122 from the Ministry of Education, Seience and Culture.

\section{References}

1) J. D. H. Strickland and T.R. Parsons: A Practical Handbook of Seawater Analysis, Fisheries Research Board of Canada, Ottawa, 1968, pp. 1-311.

2) Y. Nimura: Bull. Japan. Soc. Sci. Fish., 39, 1315-1324 (1973).

3) G. W. Snedecor and W. G. Cochran: Statistical Methods (Translated from English by $M$. Hatamura, T. Okuno, and Y. Tsumura), Iwanami, Tokyo, 1972, pp. 1-546.

4) R. J. Stevens and R. V. Smith: Water Research, 12, 823-830 (1978).

5) R. V. Smith and D. A. Stewart: Water Research, 11, 631-636 (1977). 